\title{
Tanzanian SMEs' Perceptions towards Adoption of Supply Chain Management (SCM) Strategy
}

\author{
Tumaini Mujuni Katunzi (Corresponding author) \\ Shanghai University of Finance and Economics \\ School of Information Management \& Engineering \\ 369, Zhongshan North Road No.1, Shanghai, China \\ E-mail: tumainik7@gmail.com \\ Qin Zheng \\ Shanghai University of Economics and Finance \\ School of Information Management \& Engineering \\ 777 Guoding Road, Shanghai, China \\ E-mail: qinzheng@mail.shufe.edu.cn
}

\begin{abstract}
Although a number of Small and Medium Enterprises (SME) in Tanzania economy is high, their share in national income is significantly low due to lack of efficiency. The choice to implement supply chain and supply chain management by SMEs will lower costs and increase efficiency, which will eventually help in lowering costs and increase gains to both SMEs and the country.

In this research we have compared the differences in perceptions of small and medium-sized enterprises against large enterprises. The methodology, employed was cross-sectional survey of Tanzanian enterprises engaged in agricultural processing. The findings clearly show that SMEs give less attention to supply chain management strategies, also reluctant to employ transparent integrated system to link them with other actors in the chain. Absence of compatible organization structures in SMEs is seen as a major obstacle for complete implementation of integration strategy.
\end{abstract}

Keywords: Small and medium-sized enterprises, Supply chain management, Adoption, Strategy and perceptions

\section{Introduction}

Several authors have defined supply chain management (SCM) in a variety of ways. Hong and Jeong (2006), defines SCM as a set of approaches utilized to effectively integrate suppliers, manufacturers, logistics, and customers for improving the long-term performance of individual companies and supply chain as a whole. SCM can also be defined as an actor-oriented approach focusing on how to organize and manage the flow of materials from "point of origin" to "end-user" as the point of departure (e.g. Vaaland and Heide, 2006). Arend and Wisner (2005) perceives SCM as a relation- oriented approach focusing on the relationships between the actors in the supply chain, and how co-operation and mutual interests can lead to improvements. Lastly, Lambert et al (1998) uses process-oriented approach to define SCM as "the integration of key business processes from end-user to original suppliers that provide products \& services and information that add value to customers and other stakeholders. For the purpose of this paper, our understanding of SCM is based on the relation oriented approach.

Supply chain management (SCM) has increasingly become an important way to enhance competitive strength, and it is commonly argued that present day competition is between integrated supply chains rather than individual organizations. Studies of companies exploiting the benefits of SCM have indicated improvements in individual supply chain functions ranging from 10 to 80 percent (Wagner et al., 2003). Reduced software costs, industry-wide learning of best practices and increased probability of having to compete against rivals enjoying the advantages of SCM are driving forces behind adoption of the SCM concept (Arend and Wisner, 2005).

Firms can no longer effectively compete in isolation of their suppliers and other entities in the supply chain (Lummus and Vokurka, 1998). As organizations seek to develop partnerships and more effective information 
links with trading partners, internal processes become interlinked and span the traditional boundaries of firms. The integration of key business processes among the partners in a supply chain aims at adding value for the customers. This integration is achieved by connecting suppliers, through manufacturing and assembly companies, to distributors, retailers and end-customers to make the process more efficient and the product and services more differentiated (Tan et al, 2006).

Supply chain in Small and Medium-Sized Enterprises (SMEs) is a set of business activities including purchase from open/spot market, manufacturing or processing of subcomponents/subassembly within the plant and delivery to large enterprises using hired transportation to enhance value of end product and in-turn to ensure long-term regular purchase orders. Superior features and quality, as well as superior customer service, are ways that SMEs often use to differentiate their products and services from those of the more commoditized Large Enterprises (Les) (Porter, 1985). Supply chain inefficiency is one of the most prevalent issues facing the smallto mid-size enterprise (Lewis, 2005).

A review of the background literature reveals that, many SMEs in Sub-Saharan Africa (SSA) including Tanzania, operate not in isolation but within formal and informal networks (relationships) that link them to a wider business community (see e.g. Barr (1999 Brautigam(1997). The ability of SMEs to form relationships (networks) is predicated on trust as well as cooperation and common purpose. However, the study done by Wagner et al (2003) indicates considerable diversity among SMEs with regard to implementation of SCM. In other words, SMEs do not appear to implement SCM as deeply as LEs, and consequently receive fewer advantages from other actors in the supply chain. It is in recognition of this stark reality that the need for a comprehensive study has been justified. This study has intended to investigate on the perceptions of Tanzania SMEs towards adoption of SCM practices, by examining the aspects of SCM that are perceived to be most important by SMEs. The purpose of this study is to investigate on SMEs perceptions on key aspects related to planning and control methods that support SCM, and to compare small and medium-sized enterprises with larger enterprises.

\section{Literature Review}

\subsection{SMEs' perceptions towards Supply Chain Management Adoption}

SCM requires a serious integration from planning process to order and sales. In order to be successful in supply chain management, enterprises should share their stock, production and promotion estimations and plans with customers and suppliers which form the other rings of the chain. However, most of the enterprises still avoid sharing since they fear that their rivals will obtain this information. Furthermore lack of technical knowledge in SMEs limits use of technology in supply chains. Besides, big enterprises which take place in the same chain with SMEs still experience some problems in supply chains applications although they support the system with technologies. The reasons of these problems are that SMEs in the chain have limited resources of, they want to protect themselves from competitive advantage of big enterprises and they do not their control over their assets to be restricted (Chen et al., 2004) Other problems experienced in implementation of SCM in SMEs are: lack of supplier management skills, high level of competition in supply chain, lack of cooperation in supply chains, lack of customer management knowledge, distance with the customers, distances with the suppliers, requirement of investment on information technologies by partners. Supply chains management reduces advantages which SMEs gain due to their structural features, but on the other hand it gives them opportunities for management and controlling risks (Arend and Wisner, 2005).

According to Vaaland and Heide (2006), the reasons for lack of implementation can also be related to structures in the supply chain. This includes resource structures and how various assets are linked and shared between collaborating actors. Effective resource structures are crucial when developing implicit companies and practically integrated supply chains. The second example of structural issues is reduction of inventories. These reductions easily impose significant changes in activity structures with implication for logistic structures and physical flow throughout the supply chain (Christopher, 1998).

Arend and Wisner (2005) states that SMEs in general are not able to implement SCM to its full capacity, mainly due the fact that, they are indirectly managed by larger customers and have to yield to standards specified by the buyer. This is from the notion that, since larger companies consider SMEs as easy to substitute, buyers are unenthusiastic to form partnerships with SMEs. Supply chain management is perceived by SMEs differently. Evidently, several researchers have indicated that, SMEs do not perceive their suppliers to be their partners, as big firms do; rather they perceive them to be a process which protects them against lack of production (Udomleartpresert et al., 2003).

In most of studies of SCM, size of enterprise has not been taken in consideration. Hence, there is no adequate research on to what extent SCM fits SMEs and whether it is right to implement exactly the same SCM, which is 
implemented on large enterprises, on SMEs. In the study by Arend and Wisner (2005) on to what extent small enterprises fit to supply chain application, it was found out that SMEs do not implement SCM rightly, they dot employ SCM strategies fully and they do not select SCM freely. Actually, there is a weak harmony between SMEs and SCM. Calipinar (2007), concluded that SMEs do not include bearer enterprises in strategic planning, small enterprises do not make long-term contracts, medium enterprises rarely make contracts, they do not integrate with bearers, bearer enterprises, do not develop themselves and thus they are not willing to operate in SCM in long term. As a result, bearer enterprises which are the most important factors influencing costs and on time delivery are far from being a ring of the chain.

\subsection{The Management aspects of SCM}

Planning, sourcing, making, delivering, and returning are the five components to supply chain management. Companies need a plan that is efficient in that it is cost effective, valuable to its customers, and provides high quality products or services. Finding a reliable source to deliver the goods is challenging and takes time. Making the product requires testing, packaging and preparation before it can be delivered. Delivering the product may sound easy but there are other steps involved. Educating carriers on safety through training seminars is also a good investment for the company. Creating an invoice system is also part of the delivery component. The final component is to develop a place where defective products will be returned.

Physical and technical elements represent one sub-category of the management components, and include planning and information management systems. According to Vaaland and Heide (2007), supply chain actors understand the physical and technical management component better than any other category of management elements. Hence, the physical and technical management components are appropriate for comparison of companies, and will be emphasized in this study.

Planning and control methods include collection, processing and distribution of information, both within the focal company and across company frontiers. The methods are either functional, for example, in keeping track of transportation operations, or cross functional, for example when handling order process, inventories, sourcing and invoicing. Planning and control methods are crucial for enhancing SCM competitiveness for a number of reasons. First, these methods may reduce transaction costs considerably, for example, by retrieving and processing data electronically. Secondly, the level of inventory can be lessened simply because a smooth and speedy flow of information reduces the uncertainty of the demand patterns in the flow (Lambert et al., 1997).

As it was stated in the first section the purpose of this study, is to examine the perceptions of SMEs owners towards adopting SCM strategy. More particularly, the study aims to examine the logical differences between the two groups of enterprises by employing the following research questions:

- Which benefits of SCM are considered to be most important for maintaining the competitiveness?

- Which type of information shared among supply chain actors is perceived to be most important?

- What motives are considered to be behind implementation of supply chain integration strategy?

- To what extent are activities (supporting SCM) collaborated with other supply chain actors?

- What kind of SCM competitive advantages does the management perceive to be most important?

The paper is organized in six sections continuing with methodology followed by presentations and discussions of the findings. Lastly, managerial implications, discussion on the limitations of the study, direction for further research and conclusion are presented.

\section{Methodology}

The exploratory survey was guided by the research questions formulated in the previous section. To examine the research questions stated above, the following research approach was applied: as an input for developing a survey of Tanzanian based enterprises, structured in-depth interviews were conducted in a total of 13 firms. The interviewees were top-level managers responsible for the supply chain management strategy in their respective companies, including CEOs, logistics and financial directors. Questionnaires were distributed by mail, internet and on some circumstances face- to-face interviews were conducted.

The first selection criteria for the interview sample were that the companies should represent an extensive range of industries and markets. Thus, the 13 companies came from different industries such as tobacco processing, steel, telecom, timber, paper mills, pharmaceuticals, food products, construction and cement. Secondly, the companies should be conversant with the key issues for their respective line of business. The main purpose of the interview was to identify SCM issues that are considered as important by various types of industries and provide guidance for the design of large survey, including the construction of the survey questionnaire. A draft outline of the questionnaire had been prepared in advance and was discussed in the interview. The main advice from the 
interviewees was to keep the questionnaire focused on SCM issues of general interest and tone down the use of some specified questions, particularly if these were relevant or fully understood by only some of the likely respondents. Inventory management and logistical costs are the examples of areas where questionnaire was substantially changed as a result of interview.

The questionnaire was pre-tested internally (on colleagues who were not affiliated with the study) and externally (on selected companies) before being distributed. In addition, two SCM experts provided independent assessments of the questionnaire as part of the quality assurance procedure.

\subsection{Survey Sample}

The survey sample frame was based on three sources; the Small Industries Development Organization (SIDO) and Tanzania Chamber of Commerce, Industry and Agriculture (TCCIA) databases. Questionnaires were distributed to a total of 200 companies (within the agro-processing sector).Completed questionnaires were received from 114 companies which represent a response rate of 57 percent. Thus our findings are based on analysis of data from a total of 102 companies.

Respondents were asked to report their job titles and also the names of their companies to ensure that multiple responses are not received from one company. The majority of respondents (62 percent) reported job titles specifically related to the SCM function (suppliers officer, procurement, distribution manager, etc.). The second largest group (22 percent of respondents) came from top management (general managers, owners, etc.). The third group (16 percent) consisted of respondents with administrative positions that are not specifically related to SCM (such as controller, head of administration and finance manager). As could be expected, job titles among large company respondents generally signaled senior level positions and a higher degree of specialization ( for example, "Vice President Procurement" compared to job titles like "Operations and Logistic Manager" in smaller firms.

Employment (number of employees) was used as a measure for company size. Quayle (2003) and Wagner et al (2003) define SMEs as companies with less than 200 employees, and the same cut-off point was used in this study. Eighty two percent of the companies in the sample have less than 200 employees, while the remaining 18 percent have more than 200 employees.

\section{Findings and Discussion}

\subsection{Findings}

In this part we report the main findings from the analysis. The five research questions presented earlier are examined and the results are presented in tables' 1-5. The aspects that were rated are found in Appendix 2, and the Tables include all significant differences that were found between large enterprises (LEs) and SMEs regarding the research questions. Tables' 1-5 presents means ratings of SMEs and LEs, respectively, as well as the difference between the two groups, $t$-values and significance levels. As shown in the appendix 1, all assessments were done using the same rating scale, with alternatives from $1=$ low importance to $4=$ high importance.

\section{Research question 1: Which benefits of SCM are considered to be most important for maintaining the} competitiveness?

Appendix 2 shows that the respondents were asked to rate the importance of eight different benefits of SCM as regard to maintaining competitiveness. The LEs and SMEs revealed significantly different assessments regarding the importance of these benefits. The differences were in the same direction, i.e. that the LEs considered the benefits to be more important than the SMEs did.

As presented in Table 1, within the different benefits of SCM for maintaining competitiveness, the SMEs consider reducing costs as being the most important benefit for maintaining competitiveness (3.48). Simplification of supply chain process (3.23), recovery in payment process (3.03) and recovery in distribution process (3.00) are perceived to be of medium importance. In the other hand, development in global competition (2.17), automation of the process (2.09) and standardization of process (2.08) are rated as relatively low from perception of SMEs.

Insert $<$ table 1>about here

In comparison with the large enterprises, the most apparent differences apply to standardization of process (2.08 versus 3.62), development in global competition (2.17 versus 3.46$)$ and automation of process (2.09 versus 3.31). For standardization of process the difference in mean ratings is -1.54 (2.08-3.62). A successive $t$-test reveals that this difference is highly significant, $t(113)=-6.429, \mathrm{p}<0.05$. Regarding development in global competition the 
difference in mean ratings is $-1.29(2.17-3.46)$, which is also highly significant, $t(102)=-5.206, p<0.05$. The findings could depict that Les, insist on formalized (standardized) process for the overall business process, and that they perceive SCM strategy to most fit competing globally. However the difference could also mean that SMEs, due to the nature of their business (being the raw materials suppliers of large companies) gives less attention to standardization of process, and global competition as most of them operates within their local vicinities. Less emphasis on automation of process by SMEs could the result of lack of capital and low technology characterized by this sector. The remaining benefits, recovery in purchase process, recovery in payment process, recovery in distribution process, reducing costs and simplification of supply chain process have differences that are less apparent. In general SMEs have significantly weaker stance towards benefits of SCM in sustain competitiveness than in the case of large enterprises.

\section{Research question 2: Which type of information shared among supply chain actors is perceived to be most} important?

The second research question was addressed by requesting the companies to rank, the type of information that companies are willing to share with other actors in the supply chain from the highest to the lowest. Table 2 shows the types of information where assessment by the two groups of companies differed significantly.

Insert $<$ Table $2>$ about here

As shown in table 2, SMEs consider order status for tracking information .i.e. real-time status of placed orders information (3.52) to be most important, followed by information on inventory levels (3.31). Information on capacity and capability (2.75), sales forecasting data (2.66) and performance matrix (2.36) is not given high priority by small enterprises. Large enterprises on the other hand, differ significantly with SMEs, such as the case of information on, sales forecasting data (2.66 versus 3.15), performance matrix (2.36 versus 2.69) and capacity and capability information (2.75 versus 3.08$)$ with difference of means, $-0.49,-0.33$ and -0.33 respectively.

In a general, SMEs appeared to be less enthusiastic to share some of the information with other actors in the supply chain, compared with LEs. The skepticism could be due to the fear that their rivals will obtain this information. But, more interestingly findings reveal the readiness of SMEs in sharing information on inventory levels compared to LEs (3.31 versus 3.23). One possible explanation could that SMEs are willing to share, the type of information they consider to be less risky if used against them. Consequently, LEs are willing to share information such as capability and capacity, performance matrix e.t.c. as most of these companies unlike SMEs are protected by international laws; example patent rights, fair competition and many others.

Research question 3: What motives are considered to be behind implementation of supply chain integration strategy?

As shown in Table 3, the findings indicate that, SMEs considers cost advantage (3.20) and insufficient capacity (3.07) as the top most motives behind integrating within, as well as with other actors in the supply chain. On the other hand, they perceive level of expertise and quality assurance to be the least of the reasons for implementation of supply chain integration strategy. This could be explained by the fact that, most SMEs operates in isolation and hence shows a minimum level of collaboration with customers and suppliers which form the other ring of the chain.

Insert $<$ Table $3>$ about here

Although, LEs differ significantly with small enterprises on the most important motives behind implementation of integration strategy, they both share the same opinion. The only exception is on the quality, where LEs perceive quality improvement to be most important factor behind integration, SMEs perceive it to be the least important.

\section{Research question 4: To what extent are activities (supporting SCM) collaborated with other supply chain} actors?

As represented in Table 4, SMEs are more willing to collaborate in activities concerning with replenishment and transportation \& distribution with the other actors in the chain. However, small and medium-sized enterprises are reluctant operate in collaboration for activities connected to business planning and forecasting as indicated by lower mean ratings.

Consequently, LEs emphasizes on performing business planning (3.20 versus3.78) and forecasting (2.37versus 3.70) in collaboration with other actors in the supply chain. In order to successful in supply chain management, enterprises should share their stock, production and promotion estimations and plans with customers and suppliers which represent the other loop of the chain. 
Insert $<$ Table $4>$ about here

Research question 5: What kind of SCM competitive advantages does the management perceive to be most important?

As indicated in Table 5, SMEs consider speed delivery (3.36) to be the most important SCM competitive advantage, followed by customer satisfaction (3.19). The level of integration and possession of advanced information system have been given medium importance. Again SMEs have given product quality (2.19) the least emphasis.

Insert $<$ Table $5>$ about here

The difference in perception towards, the most important competitive advantage of SCM between SMEs and LEs is significantly large on product quality -1.73(2.19 - 3.92) and advanced information system-1.35 (2.413.76). One likely, explanation for the weaker attitude shown by SMEs towards integration and having an $n$ advanced information system, could be due to lack of technical knowledge or/and limited resources. The findings from the five research question are discussed in the section that follows.

\subsection{Discussion}

In the relation to our research questions, the findings suggest the following:

- SMEs in general give less importance on the automization and standardization of planning and control systems lower than the large enterprises.

- SMEs are more reluctant to share specific type of information with other actors in the supply chain compared to large enterprises.

- Both SMEs and LEs share the same opinion on the motives behind implementation of supply chain integration strategy. SMEs places less emphasis on upstream integration.

- SMEs have displayed a weaker attitude towards, performing supply chain activities in collaboration with other actors in the ring. LEs on the other hand, put more emphasis on collaborating with customers and suppliers in the chain.

- Both groups have recognized on-time delivery as an important competitive advantage of their supply chain. However, SMEs places lower importance on product quality and advanced information system.

The aim in supply chain is formation of an enterprise series by SMEs coming together in order to minimize costs and thus reduce the competitive effect in the market (Gunasekaran et al, 2004). In this system, the enterprises which form each ring of the chain are customers of the next enterprise. From the finding, SMEs have continuously been unable to take the advantages of such a system, due to lack of trust, lower levels of integration and reluctance of implementing SCM as a whole. In order to be successful SMEs should share their stock, production and promotion estimation and plans with customers and suppliers which form the other ring o the chain. Reservation of information and avoiding use of technology reduce the speed and effectiveness of supply chains. Most of SMEs in Tanzania are less eager to employ advanced information systems, due to lack of knowledge and limited resources. Chen et al, (2004) explain that the lack of technology use by SMEs in the chain is caused by limited recourses; hence SMEs in the chain choose to protect themselves from competitive advantage of big enterprises and they do not want their control over assets to be restricted.

Tanzania's SMEs have shown a higher degree of slackness in collaborating supply chain activities with other supply chain actors compared to large enterprises. In their research on SMEs in order to determine bearer enterprises in supply chain, Keskin and others (2004) concluded that SMEs do not include bearers in strategic planning, small enterprises do not make long-term contracts, medium enterprises rarely make contracts, they do not have computer link with bearers, bearer enterprises do not develop themselves and thus they are not willing to operate in the SCM in long term. Without collaboration, each partner in the supply chain is forced to act individually, in planning the quantity, demand and delivery time to customers. This give rise to a phenomenon known as "bull-whip effect" i.e. excess of inventory or out of stock when the demand exceeds the anticipated forecast (Bowersox, et al. 2006).

Tanzania is one of the countries in Africa with enormous number of companies investing in information and communication technologies. However SMEs still rely on limited modes of communication. In our research, most small companies reveal dependence on mobile communications on dealing with orders, sales data and costumer complains across the supply chain. Extremely few small enterprises have established web-sites or any other internet connections with their suppliers and customers. This is also true for medium-sized enterprises. 


\subsection{Managerial Implications}

From our research findings it's apparent that, Tanzanian SMEs give less attention on the strategies that support SCM than LEs. One likely explanation could be that, larger companies are more organized in-terms of structures and specialization that supports implementation of SCM functions. Since supply chain management requires a serious integration from planning process to order and sales, SMEs faces fundamental challenges in achieving this objective due to slackness in adopting technology-based planning and control methods.

Our observation, further noted that SMEs lack transparency for inventory and deliveries along the whole supply network. According to Gunasekaran and Ngai (2004), material flow transparency, specifically the visibility to inventories and deliveries in the whole supply network, is considered as an important pre-requisite for successful SCM, and has been associated with significant supply chain efficiency improvements through long-terms buyer supplier relationship.

Most small businesses do not formally define or understand their competitive strategy, a factor that serves to weaken their position in their chosen market. Small firms tend not to have a lifelong learning culture or see a need for sustained improvement in organization management.

\section{Directions for further research}

This study provides a current portrait, on how the companies perceive SCM strategies and their attitudes towards its implementation. This aimed to identify systematic differences between SMEs and LEs regarding their attitudes towards adopting supply chain management strategies. However our findings are confined to agro processing SMEs, further studies should be conducted to investigate multi-category aspects within the agro-processing sector in greater detail. Other aspects of SCM such as structures and business processes would be relevant to study more closely with regards, to possible differences between small and larger companies.

\section{Conclusion}

It is an obligatory requirement for Tanzanian SMEs to adopt and implement scientific rules and principles of supply chain in order to maintain their competitiveness, operating economically, rationally and systematically. Difficulties in adopting SCM are not only observed in developing countries but also developed countries.

A detached structure of SMEs and their inability to attain a complete integration leads to problems and business process challenges. Lack of integration give rise to serious managerial economical inefficiencies, such as; high production and maintenance costs, excess as well shortage of inventories, higher lead-times on deliveries and many others.

We conclude that, Tanzania SMEs should develop and implement supply chain systems which continuously, integrate all institutions and channels from suppliers of resources to the end-user customers in harmony with their structural features in order to maintain their existence in regional, national as well as international markets.

\section{References}

Arend, R.J., and Wisner, J.D. (2005). Small business and supply chain management: is there a fit? Journal of Business Venturing, Vol. 20 No. 3, pp. 403-36.

Barr, A. (1999). Do SMEs Network for Growth? In Enterprise in Africa (King, K. and McGrath, S.) Intermediate Technology Publications, London.

Bowersox, D.J., Closs, D.J., and Cooper, M.B. (2006). Supply chain logistics management. $2^{\text {nd }}$ Ed $[\mathrm{M}]$. China Machine Press: McGraw-Hill.

Brautigam, D. (1997). Substituting for the State: Institutions and Industrial Development in Eastern Nigeria. World Development, 25(7), 1063-1080.

Çalıpınar, H. (2007). a Theoretical Model Proposal in Supply Chain Management for Turkish Reservation of information and avoiding use of technology reduce the speed and effectiveness of supply chains SMEs. Problems and Perspectives in Management, Vol.5 No2, pp 90-98.

Chen H., Themistocleous M., \& Chiu K. (2004). Approaches to Supply Chain Integration followed by SMS: An Exploratory Case Study. New York: Proceedings of the Tenth Americas Measurement. International Journal of Production Economics, 2004. No87, pp. 333-347.

Christopher, M. (1998). Logistics and Supply Chain Management, Pitman, London

Cooper, M.C., Lambert, D.M., \& Pagh, J. (1997). Supply Chain Management: More Than a New Name for Logistics. The International Journal of Logistics Management, Vol 8, Iss 1, pp 1-14 
Gunasekaran A., Patel C., and Mcgaughey R.E. (2004). A framework for supply chain performance measurement. International Journal of Production Economics, No.1 (3), pp333-347.

Gunasekaran, A., and Ngai, E.W.T. (2004). The successful management of small logistics company. International Journal of Physical Distribution and Logistics Management, Vol.33, No.9, pp 825-42.

Hong, P., and Jeong, J. (2006). Supply chain management practices of SMEs: from a business growth perspective. Journal of Enterprise Information Management, Vol. 19, pp 292-302.

Lambert, D.J., Cooper, M.C., and Pagh, J.D. (1998). Supply chain management, implementation issues and research opportunities. International of logistic management, Vol.9 No. 2, pp 1- 19.

Lewis, E. (2005). Now is SMEs' time to compete on-demand supply chain solutions that are affordable for the small distributor. Industrial Distribution, September.

Lummus, R.R., Vokurka, R.J., and Alber, K.L. (1998). Strategic supply chain planning. Production and Inventory Management Journal, Vol. 39 No. 3, pp. 49-58.

Porter, M.E. (1985). Competitive Advantage. Free Press, New York, NY.Prentice hall, 2005. pp. 830.

Tan, E.N., Smith, G., and Saad, M. (2006). Managing the global supply chain: a SME perspective. Production, Planning and Control, Vol. 17 No. 3, pp. 238-46.

Vaaland, T.I., and Heide, M. (2007). Can SME survive the supply chain challenges? Supply chain management: an International Journal, Vol. 12 No 1, and pp 20 - 31.

Wagner, B.A., Fills, I., and Johansson, U. (2003). E-business and e-supply in small and medium sized businesses. Supply Chain Management: an International Journal, Vol. 8 No. 4, pp. 343-354.

APPENDIX 1. Summary of research findings

Table 1. Which benefits of SCM are considered to be most important for maintaining the competitiveness?

\begin{tabular}{lcccc}
\hline & SME mean & LE mean & $\boldsymbol{t}$ & Mean difference \\
\hline Standardization of process & 2.08 & 3.62 & $-6.429^{*}$ & -1.54 \\
Simplification of supply chain process & 3.23 & 3.31 & $-0.654^{* *}$ & -0.08 \\
Recovery in purchase process & 2.63 & 2.85 & $-1.306^{*}$ & -0.22 \\
Recovery in distribution process & 3.00 & 3.62 & $-4.624^{*}$ & -0.62 \\
Reducing costs & 3.48 & 3.54 & $-0.329^{* *}$ & -0.06 \\
Automation of process & 2.09 & 3.31 & $-4.443^{*}$ & -1.22 \\
Recovery in a payment process & 3.03 & 3.60 & $-3.119^{*}$ & -0.59 \\
Development in global competition & 2.17 & 3.46 & $-5.206^{*}$ & -1.29 \\
Notes: $p<0.05, * * p<0.01$ & & & &
\end{tabular}

Rating scale used: 1 (low importance) to 4(high importance). This applies to all tables in this paper

Table 2. Which type of information shared among supply chain actors is perceived to be most important?

\begin{tabular}{lcccc}
\hline & SME mean & LE mean & $\boldsymbol{t}$ & Mean difference \\
\hline Sales forecasting data & 2.66 & 3.15 & $-3.138^{*}$ & -0.49 \\
Inventory levels & 3.31 & 3.23 & 0.379 & 0.08 \\
Oder status for tracking & 3.52 & 3.61 & $-0.430^{* *}$ & -0.09 \\
Capacity and capability information & 2.75 & 3.08 & $-1.886^{*}$ & -0.33 \\
Performance matrix & 2.36 & 2.69 & $-1.809^{*}$ & -0.33 \\
Notes: $* p<0.05, * * p<0.01$ & & & & \\
\hline
\end{tabular}

Table 3. What motives are considered to be behind implementation of supply chain integration strategy?

\begin{tabular}{lcccc}
\hline & SME mean & LE mean & $\boldsymbol{t}$ & Mean difference \\
\hline Cost advantage & 3.20 & $3.85^{*}$ & -4.300 & -0.65 \\
Insufficient capacity & 3.07 & $3.31^{* *}$ & -1.022 & -0.24 \\
Level of expertise & 2.83 & $3.08^{* *}$ & -1.406 & -0.25 \\
Quality & 2.68 & $3.69^{*}$ & -6.189 & -1.02 \\
Notes: $* p<0.05, * * \mathrm{p}<0.01$ & & & & \\
\hline
\end{tabular}


Table 4. To what extent are activities (supporting SCM) collaborated with other supply chain actors?

\begin{tabular}{lcccc}
\hline & SME mean & LE mean & $\boldsymbol{t}$ & Mean difference \\
\hline Business planning & 2.55 & 3.78 & $-5.359^{*}$ & -1.22 \\
Forecasting & 2.37 & 3.70 & $-5.926^{*}$ & -1.32 \\
Replenishment & 3.47 & 3.54 & $-0.416^{* *}$ & -0.07 \\
Transportation and distribution & 3.27 & 3.62 & $-2.206^{*}$ & -0.35 \\
Notes: $p<0.05, * * \mathrm{p}<0.01$ & & & & \\
\hline
\end{tabular}

Table 5. What kind of SCM competitive advantages does the management perceive to be most important?

\begin{tabular}{lcccc}
\hline & SME mean & LE mean & $\boldsymbol{t}$ & Mean difference \\
\hline Speed delivery & 3.36 & 3.60 & $-1.257^{* *}$ & -0.24 \\
Customer satisfaction & 3.19 & 3.38 & $-1.072^{* *}$ & -0.20 \\
Level of integration & 2.71 & 3.77 & $-6.443^{*}$ & -1.06 \\
Advanced information system & 2.41 & 3.76 & $-8.527^{*}$ & -1.35 \\
Product quality & 2.19 & 3.92 & $-9.865^{*}$ & -1.73 \\
Notes: $* p<0.05, * * \mathrm{p}<0.01$ & & & & \\
\hline
\end{tabular}

